\title{
Perbandingan Efek Pregabalin 150 mg dengan Pregabalin 300 mg Dosis Tunggal terhadap Nilai Numeric Rating Scale dan Kebutuhan Analgetik Pascabedah pada Pasien Histerektomi Abdominal
}

\author{
Elvidiansyah, ${ }^{1}$ Iwan Fuadi, ${ }^{2}$ Ruli Herman Sitanggang ${ }^{2}$ \\ ${ }^{1}$ Bagian Anestesi Rumah Sakit Umum Daerah Meuraxa Banda Aceh \\ ${ }^{2}$ Departemen Anestesiologi dan Terapi Intensif \\ Fakultas Kedokteran Universitas Padjadjaran/Rumah Sakit Dr. Hasan Sadikin Bandung
}

\begin{abstract}
Abstrak
Pregabalin memiliki efek antihiperalgesia, antialodinia, dan antinosiseptif. Penelitian bertujuan untuk membandingkan pregabalin $150 \mathrm{mg}$ dengan $300 \mathrm{mg}$ dosis tunggal 1 jam prabedah terhadap nyeri pascabedah dan kebutuhan opioid pada operasi histerektomi abdominal dalam anestesi umum. Uji klinik acak terkontrol buta ganda dilakukan terhadap 60 wanita (18-60 tahun) status fisik American Society of Anesthesiologist (ASA) I-II di Rumah Sakit Dr. Hasan Sadikin Bandung pada bulan Mei-Agustus 2013. Pasien dibagi menjadi dua kelompok yang menerima pregabalin $150 \mathrm{mg}$ atau $300 \mathrm{mg}$. Analisis statistik data hasil penelitian menggunakan uji-t, chi-kuadrat, dan Uji Mann-Whitney. Pada penelitian ini ditemukan nilai numeric rating scale (NRS) saat mobilisasi pada kelompok pregabalin $150 \mathrm{mg}$ dan pregabalin $300 \mathrm{mg}$ berbeda bermakna $(p<0,05)$. Pemberian analgetik tambahan pascabedah antara kedua kelompok tidak berbeda bermakna $(p>0,05)$. Simpulan penelitian adalah pregabalin dosis $150 \mathrm{mg}$ memiliki efek analgesia dan penambahan opioid yang tidak jauh berbeda dibandingkan dengan dosis $300 \mathrm{mg}$.
\end{abstract}

Kata kunci: Histerektomi abdominal, numeric rating scale, nyeri pascabedah, pregabalin

\section{Comparison of Numeric Rating Scale Value and Postoperative Analgesia Requirement between Single Dose 150 mg and 300 mg Pregabalin in Abdominal Hysterectomy Patients}

\begin{abstract}
Pregabalin has anti-hyperalgesia, anti-allodynia, and anti nociceptive effects. This study aimed to compare the use of single dose of $150 \mathrm{mg}$ pregabalin to $300 \mathrm{mg}$ pregabalin given 1 hour preoperatively in regards to postoperative pain and opioid requirements in abdominal hysterectomy patients. Double blind randomized controlled trial was conducted on 60 women (18-60 years), American Society of Anesthesiologist (ASA) physical status I-II, who underwent abdominal hysterectomy under general anesthesia in Dr. Hasan Sadikin General Hospital Bandung within May to August 2013. Patients were divided into two groups; those whose received preoperative $150 \mathrm{mg}$ pregabalin and those who received preoperative $300 \mathrm{mg}$ pregabalin. Statistical analysis was performed on the data using student's t-test, chi square, and Mann-Whitney U-test. This study found that the numeric rating scale (NRS) scores during mobilization in the $150 \mathrm{mg}$ pregabalin group and $300 \mathrm{mg}$ pregabalin were significantly different $(\mathrm{p}<0.05)$. There was no significant difference in postoperative supplemental analgesic administration between the two groups $(p>0.05)$. The conclusion of the study is there is no significant difference between preoperative $150 \mathrm{mg}$ and 300 pregabalin in its therapeutic effect and supplemental opioid requirement.
\end{abstract}

Key words: Abdominal hysterectomy, numeric rating scale, postoperative pain, pregabalin

Korespondensi: Elvidiansyah, dr., SpAn, Bagian Anestesi Rumah Sakit Umum Daerah Meuraxa Banda Aceh, Jl. Prada Utama Lorong Kelapa No.9 Banda Aceh, Telp 0651-7551180, Mobile 08116805672, Email elvidiansyah@yahoo.co.id 


\section{Pendahuluan}

Nyeri pascabedah merupakan reaksi fisiologis kompleks terhadap cedera jaringan, distensi viseral, serta respons penyakit yang dirasakan pasien sebagai suatu pengalaman sensoris dan juga emosional yang tidak menyenangkan. Nyeri pascabedah mempunyai karakteristik berupa sensitisasi di perifer serta sentral dari susunan saraf, yang lebih dikenal sebagai nyeri klinis. Sekali terjadi sensitisasi sistem saraf, makasuatustimuluslemahyangdalamkeadaan normal tidak menimbulkan nyeri akan terasa nyeri (alodinia), sedangkan stimulus kuat yang cukup untuk menimbulkan nyeri terasa amat nyeri (hiperalgesia). ${ }^{1,2}$ Sensitisasi pascabedah akan mengakibatkan penderitaan bagi pasien sehingga pada akhirnya dapat meningkatkan angka morbiditas serta mortalitas pascabedah, oleh karena itu pengelolaan nyeri pascabedah harus ditujukan ke arah pencegahan dan juga meminimalkan terjadi proses sensitisasi. ${ }^{2}$

Operasi ginekologi merupakan jenis operasi dengan derajat nyeri pascabedah yang cukup tinggi, sehingga penanganan nyeri pascabedah harus dilakukan lebih baik. ${ }^{3}$ Nyeri pascaoperasi histerektomi abdominal termasuk nyeri hebat dengan derajat nyeri 7-8 dari skala maksimal $10 .{ }^{4}$ Konsep terkini dari analgesia multimodal pascabedah adalah penggunaan opioid yang dikombinasikan dengan obat lain, antara lain non steroidal anti inflamatory drugs (NSAID) atau parasetamol, ketamin dosis rendah, serta pemberian anestetik lokal perioperatif.

Golongan NSAID cyclooxygenase-1 (COX-1) berhubungan dengan efek samping kerusakan dan perdarahan pada mukosa gastrointestinal, toksik pada ginjal, dan reaksi alergi. Golongan NSAID yang selektif terhadap cyclooxygenase- 2 (COX-2) memiliki efek protrombotik sehingga meningkatkan risiko terjadi strok dan iskemia pada miokardium. Penggunaan ketamin dapat menimbulkan efek psikogenik.

Kriteria analgetik adjuvan opioid yang ideal adalah obat yang mempunyai efek analgesia, dapat meningkatkan kualitas analgesia opioid, mengurangi toleransi dari opioid, mengurangi ansietas, serta tidak berhubungan dengan efek samping yang dimiliki oleh obat analgesi yang lain. ${ }^{5}$

Golongan yang memenuhi kriteria tersebut antara lain gabapentinoid seperti gabapentin dan pregabalin. Kedua obat ini merupakan obat yang sering digunakan sebagai antikonvulsan yang kemudian diketahui dapat dipergunakan untuk menangani nyeri akut pascabedah serta nyeri kronik. ${ }^{6}$ Pregabalin merupakan analog struktur gamma amino butyric acid (GABA) yang mempunyai efek antinosiseptif sehingga dapat dipergunakan sebagai salah satu pilihan untuk penatalaksanaan nyeri pascabedah. ${ }^{5}$

Dosis harian pregabalin berkisar 50-600 mg. Dosis pregabalin yang telah dipergunakan pada penelitian lalu sebagian besar berkisar antara $50 \mathrm{mg}$ sampai $300 \mathrm{mg} .{ }^{7}$ Pada penelitian yang membandingkan antara dosis pregabalin $75 \mathrm{mg}$ dan $150 \mathrm{mg}$ telah menyatakan bahwa premedikasi dengan menggunakan dosis 150 mg memberikan efek analgesia lebih baik pada operasi ginekologi perlaparaskopi. ${ }^{8}$ Penelitian lain membandingkan antara pregabalin $50 \mathrm{mg}$ dan $300 \mathrm{mg}$ pada 198 pasien yang menjalani odontektomi, dan didapatkan intensitas nyeri signifikan lebih baik pada kelompok pregabalin $300 \mathrm{mg} .{ }^{9}$ Penelitian yang membandingkan efek analgesia pascabedah antara pregabalin 150 mg dan 300 mg masih belum banyak dilakukan, alasan inilah penelitian ini dilakukan.

\section{Subjek dan Metode}

Penelitian ini menggunakan uji eksperimental dengan uji klinik acak terkontrol buta ganda. Pemilihan subjek berdasarkan kriteria inklusi yaitu seluruh pasien yang dirawat di Rumah Sakit Dr. Hasan Sadikin (RSHS) Bandung yang menjalani operasi histerektomi per abdominal elektif dengan anestesia umum dengan status fisik ASA I-II serta usia 18-60 tahun. Kriteria eksklusi adalah terdapat riwayat alergi serta kontraindikasi terhadap obat yang digunakan dalam penelitian, sedang mendapatkan terapi analgetik sebelumnya (opioid, parasetamol, dan juga NSAID), riwayat nyeri kronik, pusing atau nyeri kepala berulang, insufisiensi renal, serta mendapatkan terapi antiepileptik. Besar sampel ditentukan berdasarkan formula uji hipotesis 2 (dua) rata-rata, didapatkan jumlah 
sampel 30 orang untuk tiap kelompok. Analisis statistika data hasil penelitian menggunakan uji-t, chi-kuadrat, serta Uji Mann-Whitney. Data disajikan dalam mean, median, interval, serta jumlah, dan dianalisis dengan menggunakan program statistical product and service solution (SPSS) 20,0 for windows.

Penelitian dilakukan setelah mendapatkan persetujuan Komite Etik Penelitian Kesehatan Fakultas Kedokteran Universitas Padjadjaran/ Rumah Sakit Dr. Hasan Sadikin Bandung. Pemeriksaan praoperasidilaksanakan satu hari sebelum operasi, dilakukan penjelasan kepada pasien mengenai operasi serta penelitian yang dilaksanakan, dan juga dijelaskan tentang cara penilaian nyeri menggunakan numeric rating scale (NRS) serta penilaian tingkat kecemasan menggunakan hamilton anxiety rating scale (HARS).

Semua kelompok perlakuan mendapatkan premedikasi alprazolam $0,5 \mathrm{mg}$ pada malam hari. Kelompok PG15 mendapatkan pregabalin 150 mg, sedangkan kelompok PG30 diberikan pregabalin $300 \mathrm{mg}$ satu jam sebelum induksi anestesia dimulai.

Pemasangan kateter intravena dilaksanakan di ruang operasi, setelah itu diberikan cairan infus Ringer laktat untuk menggantikan puasa. Induksi anestesia dilakukan dengan propofol 2 $\mathrm{mg} / \mathrm{kgBB}$, fentanil $2 \mu \mathrm{g} / \mathrm{kgBB}$, atrakurium 0,5 $\mathrm{mg} / \mathrm{kgBB}$, setelah 3 menit kemudian dilakukan laringoskopi-intubasi. Pemeliharaan anestesia dilakukan dengan menggunakan gas isofluran 1-2 vol\% serta $\mathrm{N}_{2} \mathrm{O}: \mathrm{O}_{2} 50 \%$. Bolus intravena analgetik tramadol $1 \mathrm{mg} / \mathrm{kgBB}$ dan ketorolak $0,5 \mathrm{mg} / \mathrm{kgBB}$ diberikan saat tiga puluh menit menjelang akhir operasi. Antagonis pelumpuh otot dengan neostigmin $0,04 \mathrm{mg} / \mathrm{kgBB}$ serta sulfas atropin $0,02 \mathrm{mg} / \mathrm{kgBB}$ melalui intravena diberikan padaakhir pembedahan. Pencegahan mual muntah diberikan ondansetron 0,1 mg/ kgBB secara intravena. Analgetik pascabedah diberikan tramadol $2 \mathrm{mg} / \mathrm{kgBB}$ dan ketorolak $0,5 \mathrm{mg} / \mathrm{kgBB}$ dengan drip intravena tiap 8 jam selama 24 jam.

Penilaian skala nyeri pascabedah dilakukan dengan mempergunakan numeric rating scale (NRS) pada saat mobilisasi (duduk dan batuk) pada jam ke-1, 2, 4, 6, 12, 18, 24 pascabedah.
Pencatatan derajat nyeri, tekanan darah, laju napas, laju nadi, efek samping, penggunaan petidin tambahan, dan juga penggunaan total petidin dilakukan selama 24 jam. Bila nilai NRS lebih dari 3 diberikan analgetik penyelamatan dengan petidin $25 \mathrm{mg}$. Bila nilai NRS masih lebih dari 3, maka 15 menit kemudian dapat diberikan dosis analgetik pertolongan ulangan. Pemberian petidin dihentikan bila laju napas $<12 \mathrm{x} /$ menit atau timbul efek samping yang serius akibat pemakaian petidin.

\section{Hasil}

Analisis statistika menunjukkan bahwa untuk variabel usia, berat badan, body mass index (BMI), pendidikan serta durasi operasi kedua kelompok tidak terdapat perbedaan bermakna ( $p>0,05)$, sehingga subjek yang diteliti adalah homogen dan layak dibandingkan (Tabel 1).

Hasil pengukuran tingkat ansietas prabedah dengan mempergunakan HARS pada kelompok pregabalin $150 \mathrm{mg}$ diperoleh ansietas derajat ringan sebanyak 23 pasien dan ansietas sedang 7 pasien. Sementara pada kelompok pregabalin $300 \mathrm{mg}$ didapatkan ansietas ringan sebanyak 22 pasien dan ansietas sedang 8 pasien. Hasil pengukuran derajat ansietas prabedah pada kedua kelompok berdasarkan analisis statistik dengan uji chi-square continue correction tidak menunjukkan perbedaan bermakna $(p>0,05)$. Hasil analisis ini menunjukkan bahwa tingkat ansietas pada kedua kelompok ialah homogen sehingga kedua kelompok layak dibandingkan.

Penilaian skala nyeri pada kedua kelompok perlakuan dilakukan dengan mempergunakan NRS pada saat mobilisasi (duduk dan batuk). Rentang nilai NRS saat mobilisasi pada kedua kelompok didapatkan nilai antara 1 sampai 5. Berdasarkan hasil pengujian, diketahui bahwa nilai NRS kedua kelompok pada waktu T1, T2, T4, T6, T12, T18, dan T24 berbeda bermakna ( $\mathrm{p}<0,05$; Tabel 2). Gambaran nilai NRS saat mobilisasi terhadap waktu pengukuran pada kedua kelompok (Gambar 1; Gambar 2).

Penilaian derajat nyeri dan juga kebutuhan analgetik pertolongan selama waktu tertentu. Berdasarkan hasil analisis pengujian, diketahui 
Tabel 1 Karakteristik Umum Subjek Penelitian Kedua Kelompok Perlakuan

\begin{tabular}{lccc}
\hline \multirow{2}{*}{ Variabel } & \multicolumn{2}{c}{ Kelompok } & \multirow{2}{*}{ Nilai p } \\
\cline { 2 - 3 } & PG 15 (n=30) & PG 30 (n=30) & \\
\hline Usia (tahun) & & & 0,956 \\
Rata-rata (SD) & $43,9(7,6)$ & $43,8(6,3)$ & \\
Rentang & $31-58$ & $31-56$ & \multirow{2}{*}{0,203} \\
Berat badan (kg) & & & \\
Rata-rata (SD) & $56(6,3)$ & $53,8(6,7)$ & \\
Rentang & $40-67$ & $44-79$ & 0,256 \\
BMI (kg/m ${ }^{2}$ ) & & & \\
Rata-rata (SD) & $23,5(2,8)$ & $22,8(2,4)$ & 0,373 \\
Rentang & $19-29$ & $20-30$ & \\
Pendidikan & & & \\
SD & 7 & $7 / 30$ & \\
SMP & $7 / 30$ & $9 / 30$ & \\
SMA & $14 / 30$ & $11 / 30$ & 0,249 \\
Perguruan tinggi & $2 / 30$ & 149,30 & \\
Lama operasi & & $100-180$ & \\
Rata-rata (SD) & $141,3(29,4)$ & & \\
Rentang & $105-210$ & & \\
\hline
\end{tabular}

Keterangan: nilai p pada variabel pendidikan dihitung berdasarkan Uji Mann-Whitney. Nilai p dihitung berdasarkan uji$\mathrm{t}$ tidak berpasangan (semua data normal). Nilai $\mathrm{p}$ bermakna jika $\mathrm{p}<0,05$.

bahwa pada kedua kelompok mayoritas tidak diberikan tambahan analgetik. Pada kelompok pregabalin $150 \mathrm{mg}$ hanya 6/30 subjek yang diberikan dosis tambahan analgetik, namun pada kelompok pregabalin 300 mg hanya 4/30 subjek yang diberikan tambahan analgetik dan perbedaannya tidak bermakna ( $p>0,05$; Tabel 3). Pregabalin merupakan obat yang aman

Tabel 2 Perbandingan Nilai NRS Saat Mobilisasi antara Kedua Kelompok

\begin{tabular}{|c|c|c|c|c|c|}
\hline \multirow{3}{*}{ Waktu Pengukuran } & \multicolumn{4}{|c|}{ Kelompok } & \multirow{3}{*}{ Nilai $p$} \\
\hline & \multicolumn{2}{|c|}{ PG $15(n=30)$} & \multicolumn{2}{|c|}{ PG $30(n=30)$} & \\
\hline & Median & Rentang & Median & Rentang & \\
\hline $\mathrm{T}_{1}$ & 2 & $1-3$ & 1,5 & $1-2$ & $0,000^{*}$ \\
\hline $\mathrm{T}_{2}$ & 2 & $1-4$ & 2 & $1-2$ & $0,000^{*}$ \\
\hline $\mathrm{T}_{4}$ & 3 & $1-3$ & 2 & $1-4$ & $0,000^{*}$ \\
\hline $\mathrm{T}_{6}$ & 3 & $1-5$ & 2 & $1-4$ & $0,000^{*}$ \\
\hline $\mathrm{T}_{12}$ & 3 & $1-5$ & 2 & $1-4$ & $0,005^{*}$ \\
\hline $\mathrm{T}_{18}$ & 3 & $2-3$ & 2 & $1-5$ & $0,000^{*}$ \\
\hline $\mathrm{T}_{24}$ & 2,5 & $1-3$ & 2 & $1-3$ & $0,005^{*}$ \\
\hline
\end{tabular}

Keterangan: T1=1 jam, T2=2 jam, dan seterusnya. Nilai p dihitung berdasarkan Uji Mann-Whitney. Nilai p bermakna jika $\mathrm{p}<0,05$ 
Tabel 3 Perbandingan Pemakaian Analgetik Tambahan Antara Kedua Kelompok

\begin{tabular}{lcccc}
\hline \multirow{2}{*}{ Variabel } & \multicolumn{2}{c}{ Kelompok } & \multirow{2}{*}{ Nilai p $^{*}$} \\
\cline { 2 - 3 } & PG 15 (n=30) & PG 30 (n=30) & \\
\hline Tanpa tambahan analgetik & 24 & 26 & 0,729 \\
Dengan tambahan analgetik & 6 & 4 & \\
\hline
\end{tabular}

Keterangan: Nilai p dihitung berdasarkan uji chi-square continue correction. Nilai p bermakna jika $p<0,05$. Tanda * menunjukkan bermakna atau signifikan

dengan toleransi yang baik. Efek samping yang terjadi bergantung pada besar dosis dan juga lama pemberian. Berdasarkan hasil pengujian, pada kelompok pregabalin $150 \mathrm{mg}$ didapatkan jumlah subjek yang mengalami efek samping somnolen sebesar $8 / 30$, nausea $5 / 30$, pusing $2 / 30$, sedangkan muntah $1 / 30$. Pada kelompok pregabalin $300 \mathrm{mg}$ efek samping somnolen $16 / 30$, pusing $9 / 30$, nausea $6 / 30$, dan muntah $6 / 30$. Perbedaan proporsi pada kejadian efek samping kedua kelompok dinyatakan berbeda secara bermakna $(p<0,05)$, efek samping lebih banyak terjadi pada kelompok pregabalin 300 mg (Tabel 4).

\section{Pembahasan}

Penatalaksanaan nyeri pascabedah bertujuan memulihkan fungsi organ secara cepat serta menghindari komplikasi. Melalui manajemen nyeri yang baik akan mengurangi morbiditas dan juga komplikasi pascabedah, mobilisasi yang lebih dini, mempercepat penyembuhan,

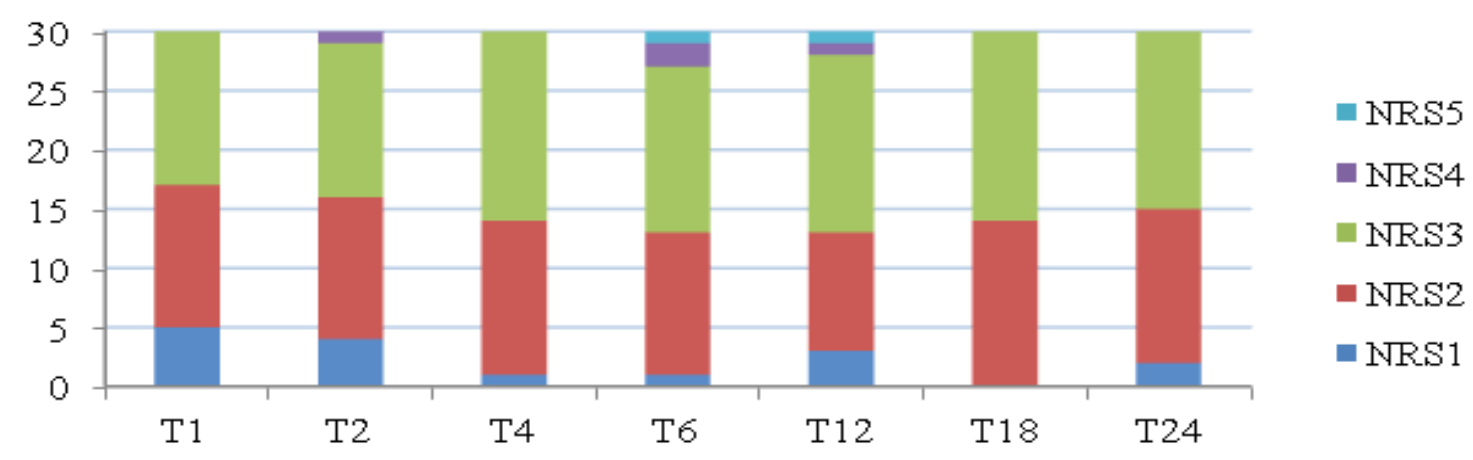

Gambar 1 Grafik Nilai NRS Saat Mobilisasi Kelompok Pregabalin 150 mg

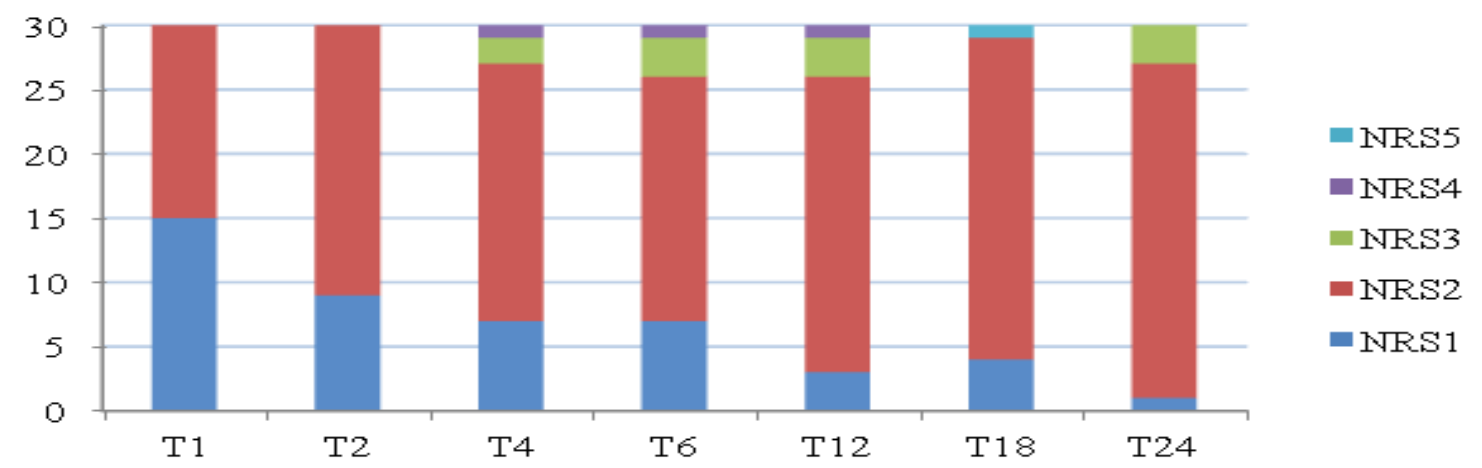

Gambar 2 Grafik Nilai NRS Saat Mobilisasi Kelompok Pregabalin 300 mg 
Tabel 4 Perbandingan Efek Samping pada Kedua Kelompok Perlakuan

\begin{tabular}{lccc}
\hline \multirow{2}{*}{ Efek Samping } & \multicolumn{2}{c}{ Kelompok } & \multirow{2}{*}{ Nilai p* } \\
\cline { 2 - 3 } & PG 15 (n=30) & PG 30 (n=30) & \\
\hline Pusing & $2 / 30$ & $9 / 30$ & \\
Nausea & $5 / 30$ & $6 / 30$ & $0,006^{*}$ \\
Muntah & $1 / 30$ & $6 / 30$ & \\
Somnolen & $8 / 30$ & $16 / 30$ & \\
\hline
\end{tabular}

Keterangan: Nilai p dihitung berdasarkan uji chi-kuadrat. Nilai p bermakna jika $p<0,05$. Tanda * menunjukkan bermakna atau signifikan

meningkatkan rasa nyamanan serta kepuasan pasien, dan juga mengurangi biaya perawatan di rumah sakit. ${ }^{10,11}$ Sampai saat ini, analgesia perioperatif berbasiskan opioid masih menjadi pilihan utama untuk mengatasi nyeri intensitas sedang dan nyeri berat. Meskipun demikian, penelitian membuktikan bahwa penggunaan opiod dosis besar erat hubungannya dengan berbagai komplikasi pascabedah. Pendekatan penanganan nyeri perioperatif melalui teknik multimodal lebih efektif dibandingkan dengan penggunaan opioid secara tunggal. ${ }^{12-14}$

Nyeri akut pascabedah sering dihubungkan dengan tipe nyeri nosiseptif, tetapi mekanisme terjadi nyeri pascabedah ternyata merupakan kombinasi mekanisme inflamasi, neurogenik, serta visceral. ${ }^{1,2}$ Pemakaian pregabalin sebagai adjuvan analgetik pascabedah telah menjadi alternatif penanganan nyeri akut pascabedah. ${ }^{6}$ Pregabalin mempunyai struktur yang analog dengan struktur GABA, tetapi tidak berikatan dengan reseptor yang sama melainkan dengan $\alpha_{2} \delta$ voltage-gated calcium channels, sehingga pregabalindapatmemberikan efekantialodinia, antihiperalgesia, dan juga antinosiseptif. Efek tersebut membuat pregabalin dapat dipakai sebagai obat tambahan analgetik pascabedah dan pencegahan nyeri kronik pascabedah. ${ }^{5}$

Pada artikel yang diterbitkan tahun 2012, terdapat 14 buah randomized controlled trial (RCT) yang mempergunakan pregabalin pada berbagai jenis operasi dalam anestesia umum maupun anestesi spinal. Dosis pregabalin yang digunakan untuk penelitian bervariasi dengan dosis $50-600$ mg/hari. ${ }^{7}$ Karakteristik umum subjek penelitian (Tabel 1) ternyata tidak menunjukkan perbedaan bermakna dalam hal usia, berat badan, BMI, pendidikan, dan lama operasi. Hal ini menunjukkan bahwa sampel penelitian ini relatif homogen secara statistika ( $p>0,05)$, sehingga kedua kelompok penelitian ini layak untuk diperbandingkan.

Ansietas memengaruhi persepsi seseorang terhadap persepsi nyeri. ${ }^{15,16}$ Pada penelitian ini dilakukan upaya untuk menghomogenkan persepsi subjek tentang nyeri, oleh karena itu dilakukan penilaian ansietas mempergunakan skala HARS yang didapatkan derajat ansietas prabedah kedua kelompok menurut statistika tidak ada perbedaan bermakna $(p>0,05)$. Hasil pengukuran ini menunjukkan bahwa derajat ansietas kedua kelompok homogen sehingga kedua kelompok layak untuk diperbandingkan.

Untuk melakukan penanganan nyeri yang tepat serta mengetahui kualitas pengurangan nyeri yang telah dilakukan maka diperlukan penilaian dan pengukuran derajat nyeri secara regular dan juga berulang sehingga membantu mengetahuiadekuat tidaknya penatalaksanaan yang telah kita diberikan. Pengukuran derajat nyeri ini sebaiknya dilakukan baik pada posisi statis maupun dinamis. Pada penilaian derajat nyeri statis berhubungan dengan kemampuan untuk beristirahat, sedangkan pada penilaian nyeri dinamis berkaitan dengan hiperalgesia mekanik serta menentukan apakah analgesia telah adekuat untuk fungsi penyembuhan. ${ }^{15}$

Pada penelitian ini melakukan pengukuran derajat nyeri dengan menggunakan numerical rating scale (NRS) yang diukur saat mobilisasi (duduk, batuk). Hasil penelitian menunjukkan bahwa kelompok pregabalin $150 \mathrm{mg}$ dan 300 
mg memiliki rentang nilai NRS saat mobilisasi yang samayaitu skala $1-5$. Setelah dilakukan Uji Mann-Whitney terdapat perbedaan bermakna pada pengukuran NRS saat mobilisasi antara kedua kelompok perlakuan.

Berdasarkan hasil perhitungan statistika terhadap nilai NRS kedua kelompok perlakuan menunjukkan bahwa terdapat perbedaan yang bermakna, namun apabila dilakukan penilaian klinis maka nilai NRS antara kedua kelompok perlakuan berada dalam rentang yang sama yaitu nyeri ringan sampai dengan sedang.

Penilaian nyeri mempergunakan skala NRS disertai penilaian jumlah kebutuhan analgetik pertolongan dalam rangka menilai kemampuan analgetik dalam memberikan analgesia yang cukup secara berkesinambungan. Pemberian adjuvan analgetika dapat menurunkan sebesar 20-50\% kebutuhan opioid pascabedah (opioid sparring effect). ${ }^{10}$

Analgetik petidin tambahan diberikan pada 6 pasien pada kelompok pregabalin $150 \mathrm{mg}$, dan 4 pasien pada kelompok pregabalin $300 \mathrm{mg}$ yang menurut perhitungan statistik perbedaan ini dianggap tidak bermakna $(p>0,05)$. Apabila dikonfirmasi dengan hasil pengukuran nilai NRS tampak bahwa pada kelompok pregabalin $150 \mathrm{mg}$ memiliki nilai NRS yang lebih tinggi dibandingkan dengan kelompok pregabalin $300 \mathrm{mg}$ dengan perbedaan tidak bermakna menurut statistika, namun demikian ternyata kebutuhan petidin tambahan kedua kelompok tersebut tidak berbeda, disebabkan analgetik pertolongan diberikan bila nilai NRS $>3$ atau nyeri dengan intensitas sedang dan berat.

Perbedaan nilai NRS tersebut berhubungan dengan dosis obat yang diberikan. Penelitian farmakokinetik pada pregabalin menunjukkan bahwa absorbsi pregabalin tidak bergantung dosis, sehingga konsentrasi pregabalin plasma akan meningkat secara linear sesuai dosis. ${ }^{17}$ Hasil penelitian ini membuktikan bahwa dosis yang lebih besar dapat menurunkan nilai NRS yang perbedaannya bermakna secara statistik, namun secara klinis kedua dosis obat tersebut tidak memberikan efek yang terlalu berbeda sehingga kebutuhan analgetik juga tidak jauh berbeda.

Pada penelitian klinis menunjukkan bahwa pregabalin merupakan obat yang sangat aman dengan toleransi yang baik serta efek samping yang timbul bergantung pada pemberian dosis, berkisar dari ringan hingga sedang, dan bersifat sementara. ${ }^{17}$ Pada penelitian ini didapatkan temuan lainnya pada kelompok pregabalin 150 mg berupa somnolen $(8 / 30)$, nausea $(5 / 30)$, pusing $(2 / 30)$ dan muntah $(1 / 30)$, sedangkan pada kelompok yang menerima pregabalin $300 \mathrm{mg}$ didapatkan somnolen (16/30), pusing $(9 / 30)$, nausea $(6 / 30)$, serta muntah $(6 / 30)$. Hasil penelitian di atas menunjukkan bahwa pada kelompok pregabalin $300 \mathrm{mg}$ mengalami efek samping yang lebih banyak dibandingkan dengan pregabalin $150 \mathrm{mg}$. Pemberian dosis pregabalin yang lebih besar mungkin dapat meningkatkan efikasinya, tetapi efek samping yang mungkin timbul akibat pemakaian dosis yang lebih besar juga menjadi meningkat. ${ }^{17}$

\section{Simpulan}

Berdasrkan hasil penelitian maka didapatkan simpulan bahwa pregabalin $300 \mathrm{mg}$ per oral ternyata lebih baik bila dibandingkan dengan pregabalin $150 \mathrm{mg}$ dalam menurunkan nilai NRS pascabedah pada histerektomi melalui abdominal, tetapi pemberian pregabalin 300 mg per oral tidak lebih baik bila dibandingkan dengan pregabalin $150 \mathrm{mg}$ dalam mengurangi kebutuhan analgetik opioid pascabedah pada operasi histerektomi abdominal.

\section{Daftar Pustaka}

1. Kirwan T. Post-operative pain. Dalam: Holdcroft A, Jaggar S, penyunting. Core topics in pain. New York: Cambridge University Press; 2005. hlm. 161-70.

2. Rao M. Acute post-operative pain. Indian J Anaesth. 2006;50(5):340-4.

3. Dolin SJ, Cashman JN, Bland JM. Effectiveness of acute post-operative pain management:I. Evidence from published data. Br J Anaesth. 2002;89(3):409-23.

4. Stephanie Yap OW, Husain A, Schmiesing C. Gynecologic oncology. Dalam: Jaffe RA, Samuels SI, penyunting. Anesthesiologist's 
manual of surgical procedures. Edisi ke4. Philadelphia: Lippincott Williams \& Wilkins; 2009. hlm. 745-83.

5. Tiippana EM, Hamunen K, Kontinen VK, Kalso E. Do surgical patients benefit from perioperative gabapentin/pregabalin? A systematic review of efficacy and safety. Anesth Analg. 2007;104:1545-56.

6. Tzellos TG, Papazisis G, Amaniti E, Kouvelas D. Efficacy of pregabalin and gabapentin for neuropathic pain in spinalcord injury: an evidence-based evaluation of the literature. Eur J Clin Pharmacol. 2008;64:851-8.

7. Zhang J, Ho KY, Wang Y. Efficacy of pregabalin in acute post operative pain: a meta-analysis. $\mathrm{Br} \mathrm{J}$ Anaesth. 2011;106(4):454-62.

8. Jokela R, Ahonen J, Tallgren M, Haanpaa M, Kottila K. Premedication with pregabalin 75 or $150 \mathrm{mg}$ with ibuprofen to control pain after day-case gynaecological laparoscopic surgery. Br J Anaesth. 2008;100(6):83440.

9. Hill CM, Balkenohl M, Thomas DW. Pregabalin in patients with post operative dental pain. Eur J Pain. 2001;2:119-24.

10. Kehlet H, Holte K. Effect of post operative analgesia on surgical outcome. $\mathrm{Br} \mathrm{J}$
Anaesth. 2001;87:67-72.

11. Sarantopoulus C. A practical approach to postoperative pain management. Dalam: Abram SE, penyunting. Pain medicine: the requisites in anesthesiology. Edisi ke-1. Philadelphia: Mosby Elsevier's; 2006. hlm. 98-113.

12. Riaz A. Multi modal analgesia technique is superior to conventional single analgesia. Professional Med J. 2007;14(3):426-31.

13. Wu CL. Acute postoperative pain. Dalam: Miller RD, penyunting. Miller's anesthesia. Edisi ke-6. Phiadelphia: Elsevier Churchill Livingstone; 2005. hlm. 2729-51.

14. Habib AS, Gan TJ. Role of analgesic adjuncts in postoperative pain management. Anesthesiol Clin N Am. 2005;23:85-107.

15. Marsaban AHM, Bagianto H, Ma'as EM. Ilmu pengetahuan dasar. Dalam: Chandra S, penyunting. Panduan tatalaksana nyeri perioperatif. Jakarta: PP IDSAI; 2009. hlm. 1-23.

16. Hamilton M. The assessment of anxiety states by rating. $\mathrm{Br} \mathrm{J}$ Med Psychol. 1959;32:50-5.

17. Gajraj MN. Pregabalin: its pharmacology and use in pain management. Anaesth Analg. 2007;105:1805-15. 